\title{
People-centred Universal Health Coverage in the Asia-Pacific
}

\author{
Calvin W. L. Ho ${ }^{1} \cdot$ Karel Caals $^{2}$
}

Published online: 4 April 2019

(C) National University of Singapore and Springer Nature Singapore Pte Ltd. 2019

Universal health coverage (UHC), variedly construed, is not a new concept. In international politics, it emerged as a global health agenda in the 1920s, became marginalised by the 1950s, but re-emerged as "Health for All" in the Declaration of Alma-Ata in 1978 (Gorsky and Sirrs 2018). The commitment then was to advance primary health care by linking health with community action, multilateral collaboration and social justice. Since then, health and health-related campaigns such as, for example, the Millennium Development Goals achieved some success, particularly in reducing the maternal mortality and under-five mortality ratios (Cha 2017). UHC remains a prominent goal in the United Nations' Sustainable Development Goals, and for good reasons. Still more needs to be done to improve the global state of primary health care, and its role in promoting the health and wellbeing of people and communities. Alarmingly, essential health services delivered through primary care are inaccessible to half of the world's population (Primary Health Care Performance Initiative 2018). In the Western Pacific Region of the World Health Organisation (WPRO), a large number of people are still "left behind" as inequities persist between urban and rural areas, and across subnational regions (World Health Organization 2017).

How can bioethics as a field contribute to UHC? This may be a fair question to ask in the light of the remark by the Director-General of World Health Organisation, Dr Tedros Ghebreyesus (2017), that: “... universal coverage is an ethical issue”. Perhaps a response to this question may be closely linked to the Astana Declaration (World Health Organization 2018), which seeks to draw the political focus back to the commitment of the Alma-Ata Declaration (World Health Organization 1978) to develop a people-centred primary healthcare as a critical step to realise health for all. If this is correct, then bioethical inquiry into the goals and implications of UHC will need to be broadened beyond its health financing aspect and related concerns in equity.

Calvin W. L. Ho

medhwlc@nus.edu.sg

1 Centre for Biomedical Ethics, Yong Loo Lin School of Medicine, National University of Singapore, Singapore

2 Department of Geography, Faculty of Arts and Social Sciences, National University of Singapore, Singapore 
Recent activities of this journal have been modest attempts at drawing in different bioethical questions and perspectives on UHC as a normative enterprise in the AsiaPacific region. Two international meetings on the theme of UHC - one in early 2018 and another in January this year - have been convened under the auspices of the Asian Bioethics Review. Different political values that have helped to shape UHC in a number of countries in the region were also discussed at the 14th World Congress of Bioethics in Bengaluru, India. Several of the papers published in this special journal issue arise from the discussions and deliberations at these events. While inadequate or a lack of financial risk protection continues to be highlighted by a number of contributors to this journal issue as an intransigent source of inequity, other dimensions of UHC that are considered include quality of care, and responsiveness of the health system in meeting people's expectations and preferences. For instance, Bridget Pratt reminds us that inclusion through public participation does not happen automatically.

If it took countries like Britain, Germany and the United States a century to attain a certain level of UHC (Bump 2015), then many Asia-Pacific countries will still have some way more to go on this journey. In view of the different demographics, sociocultural and development contexts, as well as pluralistic and often highly segmented health sectors across the region, combined with different degrees of short-term measures and longer-term aims that are to be balanced (Bloom 2019), UHC strategies are likely to be animated by very different values and considerations. While it is unclear if bioethics as a field has had any significant contribution to UHC in developed countries in Europe and North America, we hope to help secure a role for it in the Asia-Pacific regions. In this special journal issue, we document and consider UHC-related developments in China, India, New Zealand, Thailand, South Korea and Malaysia. More papers on UHC and related topics are expected to be published in subsequent issues of this journal. It is hoped that through bioethical inquiry into the ebb and flow of UHC, we will gain clearer insights on the values, choices and social arrangements that are needed for health and human flourishing.

\section{References}

Bloom, Gerald. 2019. Service delivery transformation for UHC in Asia and the Pacific. Health Systems \& Reforms 5 (1): 7-17. https://doi.org/10.1080/23288604.2018.1541498.

Bump, Jesse B. 2015. The long road to universal health coverage: Historical analysis of early decisions in Germany, the United Kingdom, and the United States. Health Systems \& Reforms 1 (1): 28-38. https://doi.org/10.4161/23288604.2014.991211.

Cha, Seungman. 2017. The impact of the worldwide millennium development goals campaign on maternal and under-five child mortality reduction: 'Where did the worldwide campaign work most effectively?'. Global Health Action 10 (1): 1267961. https://doi.org/10.1080/16549716.2017.1267961.

Ghebreyesus, Tedros Adhanom. 2017. Universal Health Coverage: A political choice. Geneva: World Health Organization. https://www.who.int/dg/speeches/2017/universal-health-coverage/en/ . Accessed 21 March 2019.

Gorsky, Martin, and Christopher Sirrs. 2018. The rise and fall of "Universal Health Coverage" as a goal of international health politics, 1925-1952. American Journal of Public Health 108 (3): 334-342. https://doi.org/10.2105/AJPH.2017.304215.

Primary Health Care Performance Initiative. 2018. Primary health care vital signs: Improvement starts with better data. https://improvingphc.org/sites/default/files/2018PHCPI_VitalSignsReport_1.pdf. Accessed 21 March 2019. 
World Health Organization. 1978. Declaration of Alma-Ata. https://www.who.int/publications/almaata declaration_en.pdf. Accessed 21 March 2019.

World Health Örganization. 2017. Monitoring Universal Health Coverage and Health in the Sustainable Development Goals: Baseline Report for the Western Pacific Region 2017. Manila: WHO Western Pacific Regional Office. https://iris.wpro.who.int/bitstream/handle/10665.1/13963/9789290618409-eng.pdf . Accessed 21 March 2019.

World Health Organization. 2018. Declaration of Astana. https://www.who.int/primary-health/conferencephc/declaration. Accessed 21 March 2019.

Publisher's Note Springer Nature remains neutral with regard to jurisdictional claims in published maps and institutional affiliations. 